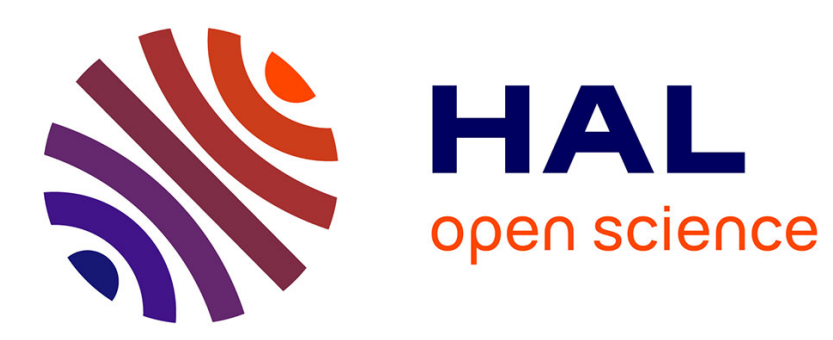

\title{
Influence of Hydrogen on the Morphology of Platinum and Palladium Nanocrystals
}

\author{
Caroline Salzemann, Petit Christophe
}

\section{To cite this version:}

Caroline Salzemann, Petit Christophe. Influence of Hydrogen on the Morphology of Platinum and

Palladium Nanocrystals. Langmuir, 2012, 28 (10), pp.4835-4841. 10.1021/la205023z . hal-01978623

\section{HAL Id: hal-01978623 \\ https://hal.sorbonne-universite.fr/hal-01978623}

Submitted on 11 Jan 2019

HAL is a multi-disciplinary open access archive for the deposit and dissemination of scientific research documents, whether they are published or not. The documents may come from teaching and research institutions in France or abroad, or from public or private research centers.
L'archive ouverte pluridisciplinaire HAL, est destinée au dépôt et à la diffusion de documents scientifiques de niveau recherche, publiés ou non, émanant des établissements d'enseignement et de recherche français ou étrangers, des laboratoires publics ou privés. 


\title{
Influence of Hydrogen on the Morphology of Platinum and Palladium Nanocrystals
}

\author{
Caroline Salzemann and Christophe Petit* \\ Laboratoire des Matériaux Mésoscopiques et Nanométriques, Université Pierre et Marie Curie-Paris 6, UMR CNRS-7070, 4 place \\ Jussieu 75252 Paris Cedex 05, France
}

ABSTRACT: Palladium and platinum nanocrystals are synthesized by the liquid-liquid phase transfer method, which is a suitable way to produce anisotropic metallic nanoparticles and control their shape at the nanoscopic scale. The process leading to shape control is, however, quite complex as all the physical and chemical parameters could play an important role. In this paper, we have demonstrated the primordial role of the dissolved gases $\left(\mathrm{O}_{2}, \mathrm{H}_{2}, \mathrm{~N}_{2}\right)$ in the solvent medium on the nanomorphology of platinum and palladium nanocrystals. In particular, it shows the specific role of $\mathrm{H}_{2}$ in the formation of platinum nanocubes.

\section{INTRODUCTION}

Inorganic nanocrystals (NCs), especially the metal ones, are widely studied and used in chemical, biological, and physical devices. Understanding their properties and exploring their application are two major driving forces behind the synthesis of a large variety of nanomaterials. ${ }^{1}$ As many of these properties are related to the surface of the NCs, efforts are underway to develop an understanding of how the shape of a nanoparticles influences its properties. In the last two decades, a large number of groups have developed new strategies to produce nanomaterials using the soft chemical route. Over the years, various methods of synthesis have been proposed. Among these, the phase transfer method developed by Brust et al. ${ }^{2}$ is one of the main soft chemical routes to produce metallic nanoparticles on a large scale. ${ }^{3-5}$ This method involves the transfer of the metal ion from a polar phase to a nonpolar phase using a transferring agent, followed by reduction in the emulsion of the metals complex.

The choice of platinum and palladium relates to their important role in chemistry: In catalysis, platinum is the most frequently used metal nowadays, but natural resources are scarce and there is a general need to minimize the use of this expensive metal. Both platinum and palladium NCs are excellent catalysts in synthetic organic chemistry, and many other applications such as environmental catalysis., ${ }^{8,9}$ Both metals are also anticipated to be hydrogen storage media for hydrogen fuel cells. ${ }^{10,11}$ For this, the size of the NCs has to be rather small, and the coating agent has to be efficient enough to prevent coalescence and weak enough not to interact too much with the nanoparticle surface. Furthermore, the crystallinity and shape of the nanoparticles can have a strong influence on the catalytic activity. Hence, larger efficiency of cubic platinum NCs in the fuel cells due to the highest efficiency of the $\{100\}$ facets has been reported. ${ }^{12}$ It is usually claimed that shape control is due to poisoning specific crystalline facets during the crystalline

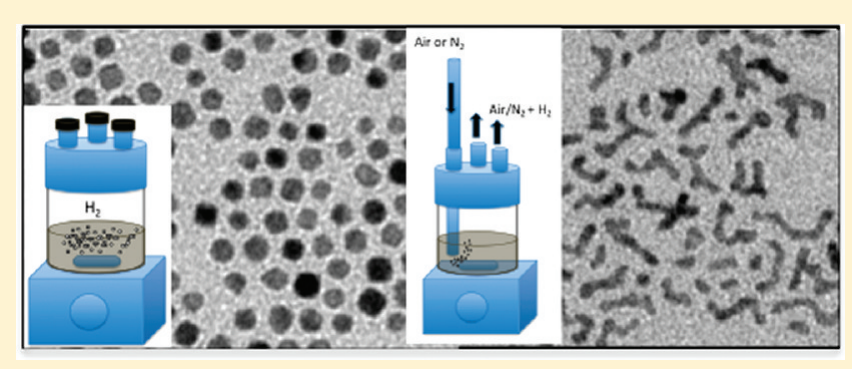

growth. ${ }^{13,14}$ Particularly, the role of $\mathrm{Br}^{-}$was mentioned in the formation of cubic metallic nanoparticles. ${ }^{15-17}$ More recently, the influence of $\mathrm{CO}$ on the shape control of metallic nanocrystals has been reported. ${ }^{14,18}$ Thus, gases could control the shape of the nanocrystals. We show here that, even if $\mathrm{Br}^{-}$ could play a role, other parameters are predominant in shape control. Here, we will examine the influence of environmental conditions, mainly the role of the dissolved gases $\left(\mathrm{O}_{2}, \mathrm{H}_{2}, \mathrm{~N}_{2}\right)$ in the solvent medium on the shape of platinum and palladium NCs made by the wet chemistry route. This shows the specific role of $\mathrm{H}_{2}$ on the nanomorphology of platinum and palladium.

\section{EXPERIMENTAL PROCEDURES}

Pd and Pt nanocrystals are synthesized by the phase transfer synthesis method presented by Brust et al. ${ }^{2}$ Typically, it consists of metal ion transfer from an aqueous phase to an organic phase using an extractant molecule. The nanocrystals are obtained by chemical reduction.

2.1. Preparation of the Metallic Salt Solution. Aqueous solutions of $0.05 \mathrm{M} \mathrm{PtCl}_{4}$ and $\mathrm{PdCl}_{2}$ were prepared by dissolving the metallic salt in acid media to form the complexes $\mathrm{H}_{2} \mathrm{PtCl}_{6}$ and $\mathrm{H}_{2} \mathrm{PdCl}_{4} \cdot{ }^{19,20}$ These aqueous solutions were then mixed with $2 \times 10^{-2}$ $\mathrm{M}$ tridecylammonium bromide (TDAB) dispersed in $80 \mathrm{~cm}^{3}$ of toluene. To ensure maximum transfer of metal ions from the water phase to the organic phase, the transferring agent (TDAB) was present in large excess (corresponding to TDAB: $\mathrm{PtCl}_{4} / \mathrm{PdCl}_{2}=2.5: 1$ ). The two-phase mixture was vigorously stirred until all the metallic complexes were transferred into the organic phase $(30 \mathrm{~min})$. The colorless water phase is then discarded.

2.2. Chemical Reduction of the Metallic Salt. Procedure I: Reduction in the Presence of Capping Agent (Figure 1A). $6.52 \times$ $10^{-3}$ mol of dodecylamine $\left(\mathrm{C}_{12} \mathrm{NH}_{2}\right)$ Capping Agent (CA) is added under stirring to $20 \mathrm{~cm}^{3}$ of the obtained organic solution

Received: December 20, 2011

Revised: February 17, 2012 


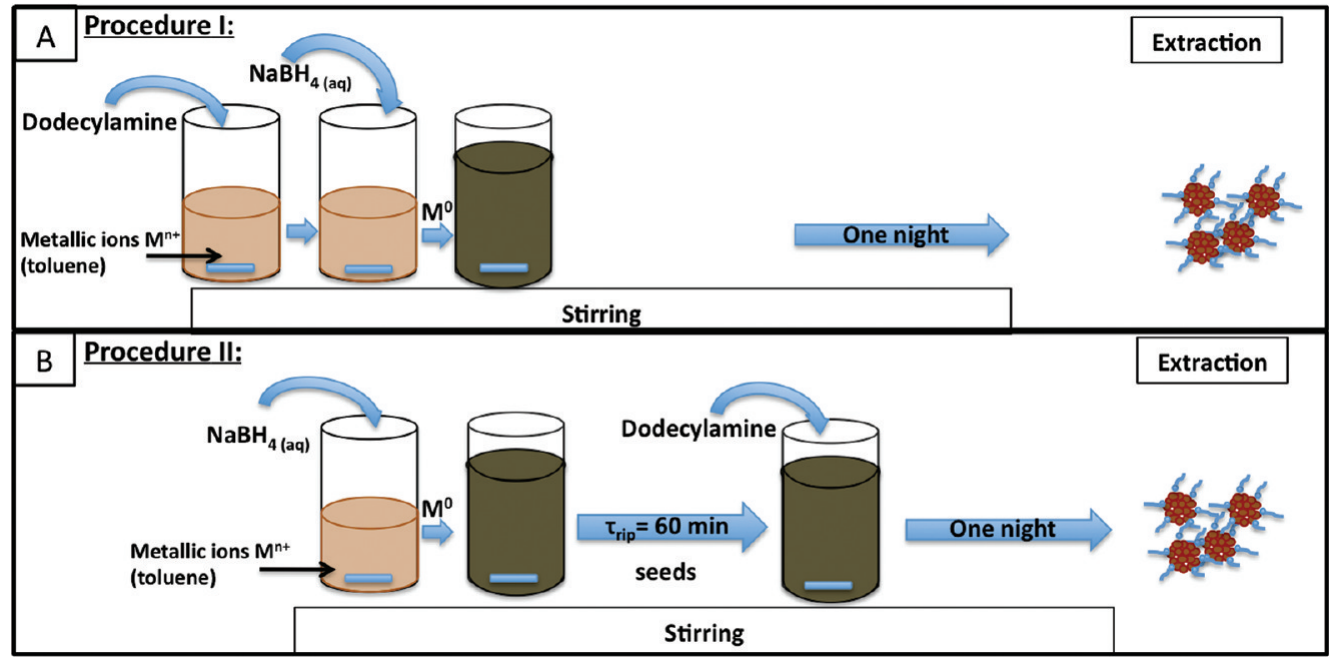

Figure 1. Schematic description of the two procedures used to synthesized metallic nanoparticles. For procedure I, the capping agent is added before the reducing agent (A), whereas in procedure II, the capping agent is added one hour after the addition of the reducing agent (B).

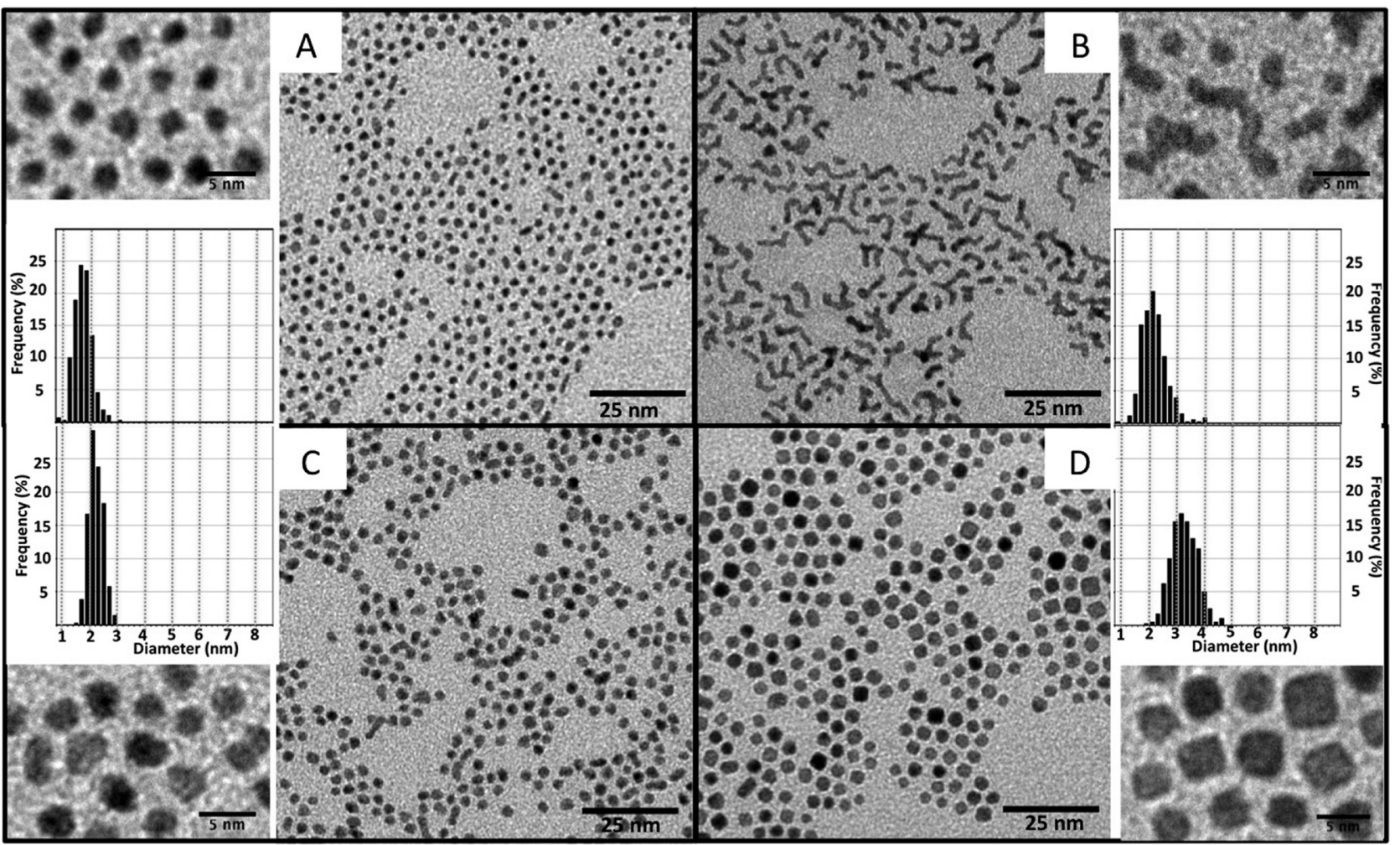

Figure 2. Pt nanocrystals obtained after extraction and redispersion in toluene. Pt nanocrystals produced in open air under oxygen flow from procedure I (A) or procedure II (B) and Pt nanocrystals produced under hydrogen (glovebox) from procedure I (C) or procedure II (D). Higher TEM magnification and corresponding size distributions are presented in insets.

containing the metallic complexes. A freshly prepared aqueous solution of $\mathrm{NaBH}_{4}\left(10 \mathrm{~cm}^{3}, 0.4 \mathrm{~mol} \cdot \mathrm{L}^{-1}\right)$ is dropwise added under stirring, yielding an emulsion. This induces the reduction of the metallic salt at the interface of the organic and aqueous phases. Both the reducing agent and the capping agent are added in large stoichiometric excess relative to the palladium/ platinum $\left(\mathrm{NaBH}_{4}: \mathrm{Pd} / \mathrm{Pt}=17: 1\right.$ and $\left.\mathrm{CA}: \mathrm{Pd} / \mathrm{Pt}=22: 1\right)$. The emulsion turns relatively rapidly from orange to dark brown. The reaction takes place for one night, after which the stirring is turned off and the organic phase, containing the metal nanoparticles, is collected and evaporated using a Rotavapor. The black paste obtained is then washed with $40 \mathrm{~cm}^{3}$ of ethanol. Then, the turbid solution is centrifuged and the supernatant is discarded. This operation is repeated twice. After the last centrifugation, the precipitate is redispersed in $4 \mathrm{~cm}^{3}$ of toluene. The final solution contains the coated $\mathrm{C}_{12} \mathrm{NH}_{2}$ nanoparticles in toluene.

Procedure II: Reduction Followed by the Addition of Capping Agent (Figure 1B). In this case, the freshly prepared aqueous solution of $\mathrm{NaBH}_{4}\left(10 \mathrm{~cm}^{3}, 0.4 \mathrm{~mol} \cdot \mathrm{L}^{-1}\right)$ is dropwise added under stirring to $20 \mathrm{~cm}^{3}$ of the organic solution containing the metallic complexes. The reduction occurs in the emulsion phase, at the interface of the organic and aqueous phases, which results in a color change from orange to dark brown. After $60 \mathrm{~min}$ (ripening time $\tau_{\text {rip }}$ ), $6.52 \times 10^{-3} \mathrm{~mol}$ of dodecylamine $\left(\mathrm{C}_{12} \mathrm{NH}_{2}\right)$ capping agent is then added. The chemical 
Table 1. Size and Size Distribution of Extracted Pt and Pd NCs Obtained from Procedure I and Procedure II in the Presence of $\mathrm{O}_{2}$ and $\mathrm{H}_{2}$

\begin{tabular}{|c|c|c|c|c|}
\hline & \multicolumn{2}{|c|}{$\mathrm{Pt}$} & \multicolumn{2}{|c|}{$\mathrm{Pd}$} \\
\hline & Air & $\mathrm{H}_{2}$ & Air & $\mathrm{H}_{2}$ \\
\hline Proc I & $1.8 \pm 0.3 \mathrm{~nm}$ & $2.3 \pm 0.3 \mathrm{~nm}$ & $1.9 \pm 0.3 \mathrm{~nm}$ & $3.0 \pm 0.4 \mathrm{~nm}$ \\
\hline Proc II & $1.8 \pm 0.3 \mathrm{~nm}$ & $3.2 \pm 0.5 \mathrm{~nm}$ & $5.2 \pm 0.9 \mathrm{~nm}$ & $2.4 \pm 0.5 \mathrm{~nm}$ \\
\hline
\end{tabular}

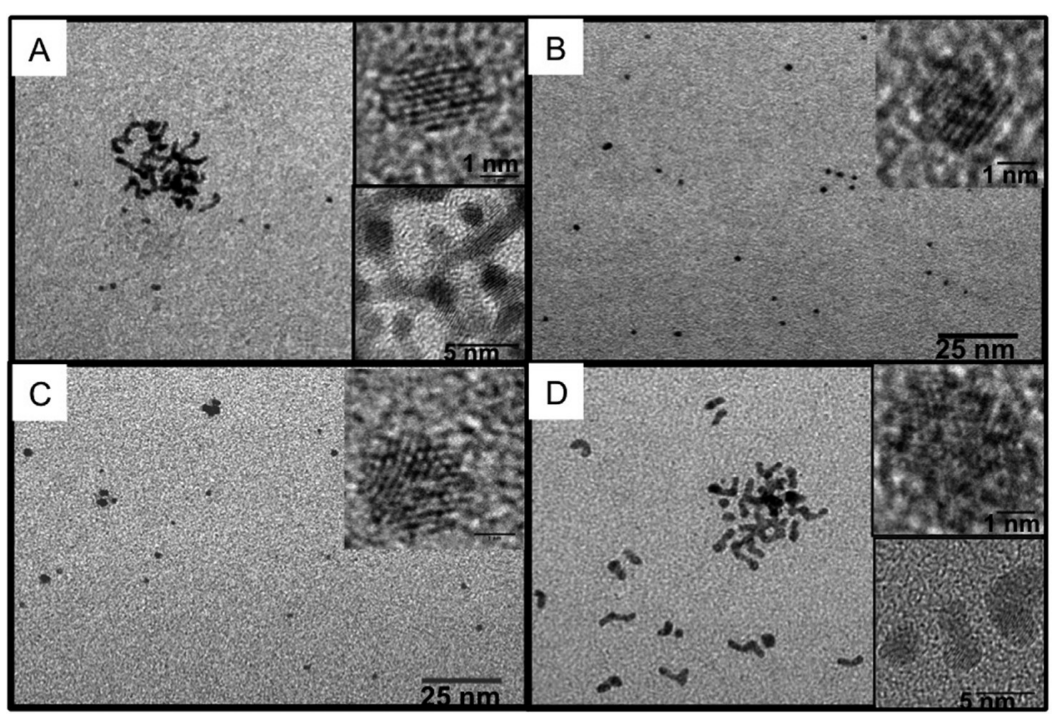

Figure 3. TEM and High Resolution TEM of seeds obtained after one hour of reduction, just before the addition of the capping agent. Pt seeds obtained in open air under oxygen flow (A) and under Hydrogen (glovebox) (B) and Pd seeds obtained in open air under oxygen flow (C) and under Hydrogen (glovebox) (D).

bath is kept under stirring for one night, then the nanocrystals are extracted following the procedure described above. The final solution contains the coated $\mathrm{C}_{12} \mathrm{NH}_{2}$-nanoparticles in toluene.

2.3. Environmental Effect. The synthesis of Pt/Pd NCs has been performed either under oxygen (air flow) or in the absence of oxygen (in a glovebox), under hydrogen atmosphere or under $\mathrm{N}_{2}$ flow. In this last case, degassed solutions are used.

Hydrogen is naturally produced by the chemical reduction. To perform the reaction under saturated $\mathrm{H}_{2}$ atmosphere, a closed screw cap with three ports is used and the reducing and capping agents are injected through a silicone septum. In order to see the influence of hydrogen atmosphere on the nanoparticles, we performed the same syntheses with open screw cap and by bubbling $\mathrm{N}_{2}$ into the chemical bath, during and after the reduction, to drive out the hydrogen formed. The same procedure is used for oxygen except that the syntheses are made in open air under air flow.

\section{RESULTS AND DISCUSSION}

Reducing metallic salt by $\mathrm{NaBH}_{4}$ is a well-known method to produce hydrogen. The borohydride ion spontaneously hydrolyzes in aqueous solution to give hydrogen as follows:

$$
\mathrm{BH}_{4}{ }^{-}+2 \mathrm{H}_{2} \mathrm{O} \rightarrow \mathrm{BO}_{2}^{-}+4 \mathrm{H}_{2}
$$

This reaction is rather slow in pure water; ${ }^{21}$ however, the presence of metal salts can catalyze or participate in this decomposition yielding the formation of metallic particles. ${ }^{22}$ This last process is considerably faster. ${ }^{21}$ The chemistry of the borohydride reduction of metal ions has been found to be quite complex, and the nature of the products depends on the experimental conditions, ${ }^{23}$ but in any case, $\mathrm{H}_{2}$ is one of the products of the reaction. Indeed, there are at least 4 mol of $\mathrm{H}_{2}$ formed from $1 \mathrm{~mol}$ of $\mathrm{NaBH}_{4}$, which in turn could produce, in a closed vessel, a high pressure of hydrogen. ${ }^{24}$ It is known that
$\mathrm{H}_{2}$ strongly interacts with noble metal as platinum and palladium. This is one of the driving forces of their use in catalysis and notably for fuel cells. ${ }^{10,11}$ Thus, we must ask ourselves about the influence of $\mathrm{H}_{2}$, produced during the reaction, on the structure of the metallic NCs formed from colloidal chemistry (shape, size, and so forth). For that, we develop a synthetic procedure, which allows us to focus on the role of the dissolved gas on the morphology of platinum and palladium NCs. It has been previously reported that synthesis of cubic platinum NCs could not be achieved from colloidal systems in the open air. ${ }^{16}$ Continuously bubbling air (i.e., $20 \%$ of $\mathrm{O}_{2}$ ) or nitrogen (under glovebox) in the chemical bath, using an open vessel, allows us to drive out the hydrogen formed during the reaction and then to compare the role of these two gases. In a second step, operating under nitrogen glovebox and working with degassed solutions in closed vessels allows us to investigate, by comparison, the specific role of $\mathrm{H}_{2}$.

3.1. Synthesis of Platinum NCs in Open Air. Metallic nanocrystals can be synthesized considering two procedures (Figure 1): the capping agent (dodecylamine $\mathrm{C}_{12} \mathrm{NH}_{2}$ ) is added either before (procedure I, Figure 1A) or one hour after (i.e., the ripening step) the addition of the reducing agent (procedure II, Figure 1B). Figure 2 shows the coated Pt NCs obtained after extraction and their redispersion in toluene. They are synthesized in open air under oxygen flow. Faceted $\mathrm{Pt}$ NCs characterized by a diameter of $1.8 \pm 0.3 \mathrm{~nm}$ are obtained from procedure I (Figure 2A and inset; Table1). Differently, in procedure II, where the capping agent is added one hour after the reduction, wormlike particles having the same crosssectional diameter of $1.8 \pm 0.3 \mathrm{~nm}$ are observed (Figure 2B, Table1). This is surprising, because in the liquid-liquid phase transfer synthesis, adding the capping agent after the reducing 
agent usually leads to larger spherical NCs. ${ }^{25}$ This observation shows that, during the ripening time (one hour), no condensation growth occurs, but rather a growth by aggregation of the $1.8 \mathrm{~nm}$ nanoparticles. This indicates that the initial seeds are limited in growth but can aggregate to form wormlike structure having the same lateral size. Such behavior has already been observed for Pt nanoparticles synthesized in open air in other colloidal systems such as reverse micelles. ${ }^{19}$ To confirm this assumption, TEM and HRTEM have been carried out on the seed obtained from procedure II, just before the addition of the capping agent $\mathrm{C}_{12} \mathrm{NH}_{2}$ (Figure 3 ). In this case, a drop of solution is taken directly from the chemical bath and deposited on a TEM grid. Figure 3A shows that both isolated faceted and wormlike Pt nanoparticles are observed. HRTEM (inset Figure 3A) clearly confirms that wormlike particles are composed of aggregated nanocrystals, which are characterized by an FCC structure and are similar to the isolated one. It confirms also that this aggregation appears during the ripening step. Thus, adding the capping agent only allows stabilization of the wormlike structure, which can be extracted. In procedure I, the capping agent is added prior to the reducing agent, so that the initial growth of the seeds occurs in the presence of the capping agent, which in turn prevents the aggregation, yielding isolated quasi-spherical nanocrystals (Figure 2A). Clearly, the order of addition of reagents plays an important role in controlling shape.

3.2. Synthesis under Nitrogen Atmosphere: The Role of Hydrogen and Nitrogen. Similar syntheses of Pt NCs are performed in the absence of oxygen, under hydrogen atmosphere. If the reducing agent is added before (procedure I), the Pt nanoparticles obtained are similar, but somewhat larger $(2.3 \pm 0.3 \mathrm{~nm})$ than under oxygen (Figure 2C, Table 1). The effect of hydrogen is, however, greatly evidenced in procedure II as instead worms, cubic NCs of $3.2 \pm 0.5 \mathrm{~nm}$ (Figure 2D, Table 1), are obtained. Different from what is observed under oxygen, larger particles are obtained from procedure II as expected (see above), but now the shape is strongly modified. In procedure II, the growth of the NCs results from condensation of the atoms on the first seeds; usually, this yields quasi-spherical NCs. Formation of cubic NCs, in an isotropic liquid medium, could only be understood if some species interact with the initial fcc-crystallized seeds to direct a selective growth of the (111) facets and prevent the growth of the (100) facets. In the literature, it is often claimed that $\mathrm{Br}^{-}$leads to cubic nanomorphology through its adsorption on the (100) faces. ${ }^{15,17,26}$ In our case, $\mathrm{Br}^{-}$is always present in the chemical bath regardless of the dissolved gas used, but cubes are only observed under $\mathrm{H}_{2}$ atmosphere. Then, the exclusive role of this ion on the nanomorphology control of the Pt nanoparticles can be excluded. In addition, Peng et al., in a recent monograph, report different liquid synthesis leading to the formation of cubic platinum nanoparticles. It appears that many of them involve the presence of $\mathrm{H}_{2} \cdot{ }^{27}$ Indeed, platinum cubes can be obtained without the presence of $\mathrm{Br}^{-}$but never in the absence of $\mathrm{H}_{2}$. Different from synthesis under $\mathrm{O}_{2}$ flow, the TEM and HRTEM made on the seeds deposited after one hour of reduction (i.e., just before adding the capping agent) show the formation of only small, isolated faceted particles wellcrystallized in an FCC structure (Figure 3B and insets). This means that the aggregation is inhibited through the stabilization of the nanoparticles. At this step, no dodecylamine is present in solution, but only ions (such as $\mathrm{Br}^{-}$) and/or the dissolved gas $\left(\mathrm{H}_{2}\right)$. Compared with the same synthesis in open air, under a permanent flow of $\mathrm{O}_{2}$ the only change in the chemical bath is the dissolved gas. The absence of worms through the stabilization of nanoparticles could then be attributed to the presence of $\mathrm{H}_{2}$, which adsorbs at the metallic surface of the fcc platinum seed. It is well-known that $\mathrm{H}_{2}$ adsorbs spontaneously and strongly to the Pt surfaces. ${ }^{28,29}$ Its affinity for the Pt surface is higher than $\mathrm{O}_{2}{ }^{30}$ Thus, isolated well-crystallized Pt FCC seeds are present in solution (Figure $3 \mathrm{~B}$ ) and can grow slowly, after the adding of the dodecylamine and prior to the extraction from the chemical bath $16 \mathrm{~h}$ after (Figure 1B). This growth occurs in the presence of $\mathrm{Br}^{-}$and dodecylamine under highpressure $\mathrm{H}_{2}$, yielding platinum nanocubes. At this step, the system behaves like a microemulsion, where TDAB and dodecylamine form the interface. It has been previously demonstrated that long chain alkylamine $(n \geq 14)$ stays at the interface making the palisade layer static as compared to the palisade layer formed with the short chain alkylamines. ${ }^{19}$ This effect is analogous to the one seen for other surfactant systems, where the lifetime of the colloidal aggregate has been found to depend on the length of an added co-surfactant. ${ }^{31}$ A more dynamic interface will favor the growth of the initial seeds either by transport of new platinum-TDA complexes from the bulk toluene phase into the interface of the water droplets, where they release platinum to the growing nanoparticle, ${ }^{19}$ or by the condensation of the monomer $\mathrm{Pt}^{0}$. Thus, decreasing the lifetime of the capping agent into the palisade layer in the chemical bath favors homogeneous growth of the NCs prior to their extraction. Indeed, decreasing the adsorption of dodecylamine, which is only weakly bound to the platinum surfaces, ${ }^{32}$ will decrease the lifetimes of the capping agent at the interfaces and thus favors the controlled growth of the FCC seeds yielding nanocubes. It has been reported that the presence of adsorbed $\mathrm{H}_{2}$ excess on a platinum surface increases the mobility of $\mathrm{NH}_{2}$ at surfaces (i.e., decreases the lifetime at the surfaces). ${ }^{23}$ Thus, in our case, where a large amount of $\mathrm{H}_{2}$ is present, we can assume a decrease of the lifetime of dodecylamine at the interface compared to synthesis under $\mathrm{O}_{2}$ flow.

In procedure $\mathrm{I}$, the coating agent is present prior to the reduction (Figure 1A). During the reduction, $\mathrm{Pt}^{0}$ atoms and $\mathrm{H}_{2}$ will be produced simultaneously in the presence of amine, and then a competition between $\mathrm{H}_{2}$ and dodecylamine adsorptions at the metallic surface arises. Different from synthesis under $\mathrm{O}_{2}$ flow, the larger size obtained under $\mathrm{H}_{2}$ shows that the capping agent does not block the growth of the nanoparticles. This confirms the assumption made above that the interface between $\mathrm{C}_{12} \mathrm{NH}_{2}$ and the metallic surface under $\mathrm{H}_{2}$ is more dynamic than in the open air and/or that the affinity of $\mathrm{H}_{2}$ is strong enough to desorb the dodecylamine and then allows the NCs to continue their growth before the extraction.

Thus, $\mathrm{H}_{2}$ plays a double role in the growth: first, it protects initial seeds from the aggregation (Figure 3B); and second, by decreasing the adsorption of the capping agent, it favors controlled growth on (111) facets in the presence of the capping agent and $\mathrm{Br}^{-}$, yielding the cubic shape. To confirm the specific role of $\mathrm{H}_{2}$, similar investigations have been undertaken, in a glovebox with degassed solution, but under $\mathrm{N}_{2}$ flow in open vessels, to drive out the $\mathrm{H}_{2}$ formed during the reaction. Figure 4A shows that, in this case, procedure II yields wormlike structure similar to that obtained in open air, under $\mathrm{O}_{2}$ flow: no specific shape as cubes is obtained. HRTEM and TEM show the seeds prior to the addition of capping agent (Figure 4B and insets). Again, they are similar to that obtained under $\mathrm{O}_{2}$ flow in open air. Thus, $\mathrm{N}_{2}$ cannot protect the seeds from 


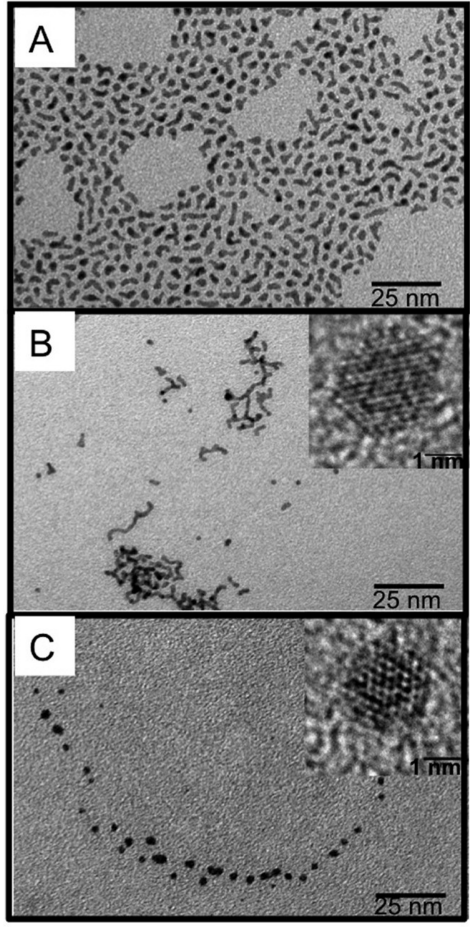

Figure 4. Nanocrystals produced under nitrogen flow (under glovebox) from procedure II. TEM images of Pt nanocrytals obtained after extraction (A). The Pt (B) and Pd (C) seeds obtained before the addition of capping agent and their HRTEM in inserts.

aggregation, and finally, wormlike structures are obtained at the end of the reaction. This confirms the specific role of hydrogen in the control of nanomorphology of platinum NCs. We cannot exclude a kinetic effect on the morphology of the metal nanoparticles, as the reduction rate of the metal can vary in the presence of $\mathrm{H}_{2}$. However, the reduction step is fast (at the minute scale), compared to the growth process, which takes place in $16 \mathrm{~h}$ (after addition of the capping agent). In fact, the growth kinetics is complex and is always an open field. As an example, the final size of the nanocrystals strongly depends on the aging time before the extraction. Furthermore, preliminary in situ investigation of the growth process by X-ray scattering measurements indicates the presence of $\mathrm{O}_{2}$ in the solution, totally inhibiting the growth process after addition of the capping agent, when under $\mathrm{H}_{2}$ it takes places in $16 \mathrm{~h}$ leading to the cubic shape. ${ }^{33}$ This confirms the predominant role of $\mathrm{H}_{2}$ in the growth of the platinum nanocubes.

3.3. Case of Palladium Nanocrystals. As for platinum, palladium is often used in catalysis even in combination with platinum. They belong to the same chemical group, but their behavior differs especially concerning the interaction with $\mathrm{H}_{2}$. Contrary to platinum, palladium can not only adsorb, but also absorb large quantities of hydrogen. In fact, $\mathrm{H}_{2}$ can dissociate at surfaces, and then atomic $\mathrm{H}$ can diffuse into the lattices to form hydrides, $\mathrm{PdH}_{x}{ }^{34}$ This occurs at a pressure lower than 1 bar and at room temperature. It has been recently reported that, when the size of the $\mathrm{Pd}$ particle approaches the nanometric scale, the probability of forming Pd-hydrides increases compared to the bulk state. This is due to the high specific surface area in the case of the nanoparticle. Indeed, the presence of $\mathrm{H}_{2}$ changes the structure of the surface, which is no longer metallic and becomes amorphous. ${ }^{35}$ Thus, as the shape control and the growth process in liquid-liquid phase transfer synthesis is strongly dependent on binding of the capping agent on the metallic surfaces (see above), we can expect different behavior in the case of palladium as the anchoring of the capping agent depends on the state of the surfaces.

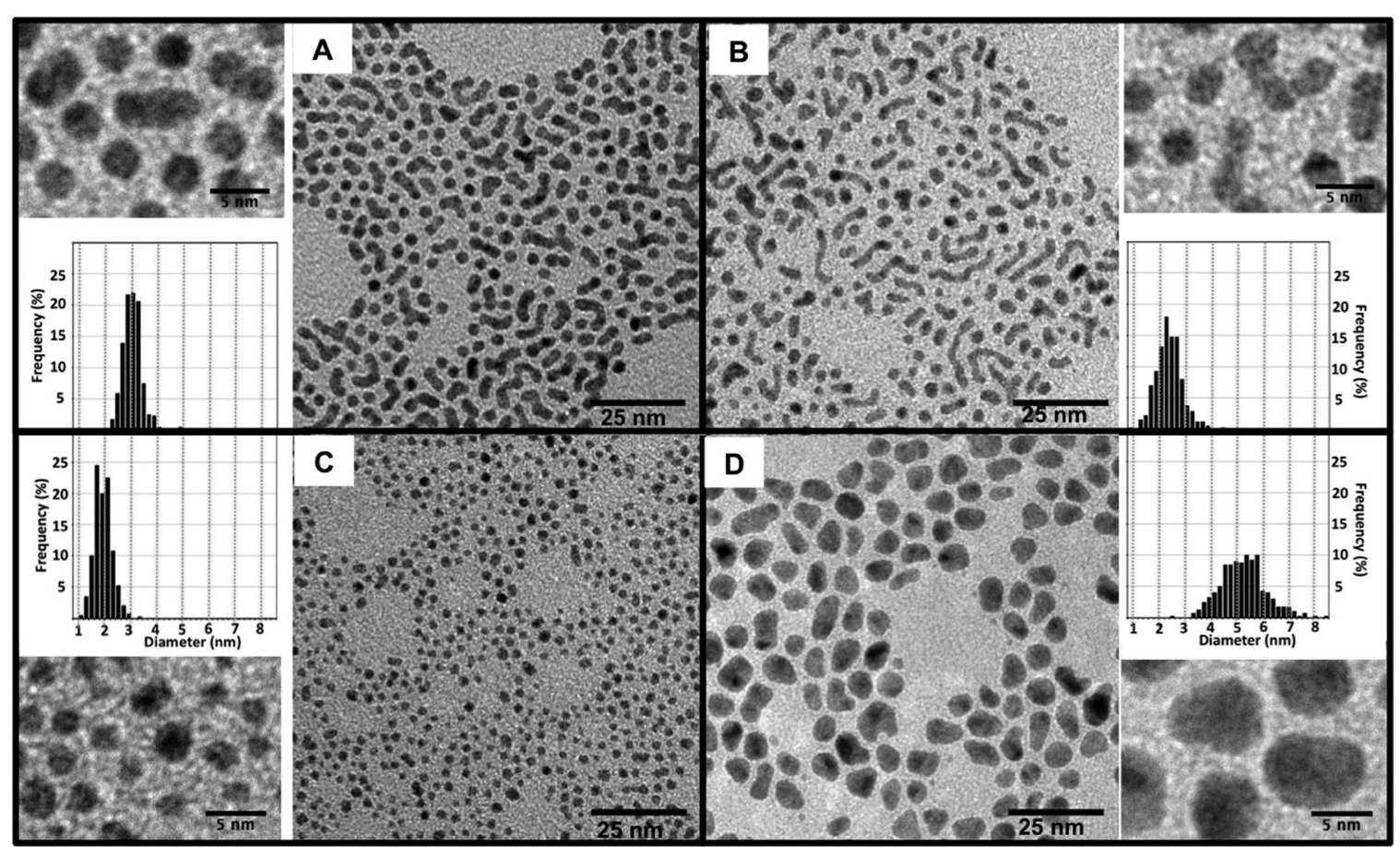

Figure 5. Pd nanocrystals obtained after extraction and redispersion in toluene. Pd nanocrystals produced in open air under oxygen flow for procedure I (A) or for procedure II (B) and Pd nanocrystals produced under hydrogen (glovebox) for procedure I (C) or for procedure II (D). Higher TEM magnification and corresponding size distributions are presented in insets. 
Figure 5 shows the coated Pd NCs after extraction and redispersion in toluene. They are obtained in a glovebox under hydrogen for procedure I (Figure 1A) and procedure II (Figure 1B). Spherical particles with a few short worms, characterized by diameter and/or cross-sectional diameter of $3.0 \pm 0.4 \mathrm{~nm}$, are observed from procedure I (Figure 5A). Similar morphologies are obtained from procedure II, but particles are characterized by a lower size $(2.4 \pm 0.5 \mathrm{~nm})$ instead of a larger expected, as the capping agent is added $1 \mathrm{~h}$ after the reducing agent (Figure 5B, Table 1). Different from the case of platinum, no specific shape is observed. The seeds, observed at the end of the ripening step without capping agent, are mainly wormlike (Figure 3D) and the HRTEM (insert Figure 3D) shows a crystallized FCC core with an amorphous shell. As explained above, this amorphization of the surfaces could be due to $\mathrm{H}_{2}$ absorption, leading to palladium hydride. It is not due to the nature of the materials, as the same experiments made under $\mathrm{O}_{2}$ flow (Figure 3C) or $\mathrm{N}_{2}$ flow (Figure 4C) show that the seed are perfectly crystallized without this core-shell structure.

It is known that self-assembled monolayers could only be obtained on well-crystallized surfaces. Thus, in our case as the surface of nanoparticles is amorphous, the capping layer should present numerous defects and/or its binding with the surface (hydride) differs from that of pure metal. As a consequence, dodecylamine layer cannot protect efficiently from aggregation. This yields wormlike structures coexisting with spherical ones, whatever the synthetic procedure is.

Surprisingly, the characteristic size decreases in procedure II compared to procedure I. Again, this is probably an effect of hydrogen absorption. Here, as the coating agent is added $1 \mathrm{~h}$ after the reducing agent, the seeds of palladium are exposed to high pressure of $\mathrm{H}_{2}$, which yields formation of hydride. ${ }^{34,35}$ This effect is even more important as the size decreases. ${ }^{35}$ Thus, this change in the surface could inhibit the growth by condensation of $\mathrm{Pd}^{0}$ on the seed. However, as the dodecylamine is only weakly bound to the surfaces, it cannot prevent aggregation of palladium hydride NCs. In this case, the growth process is similar to what has been observed for platinum in open air (Figure 2B). For procedure I, the coating agent is present prior to the reduction (Figure 1A). Hence, there is competition between $\mathrm{H}_{2}$ and dodecylamine: to form hydride, hydrogen must first desorb the dodecylamine, but this process is not blocked by the capping layer. ${ }^{34}$ This is due to weak interaction of the amine group with the metallic surfaces. Thus, in this case, dodecylamine partly passivates the surfaces allowing the NCs to grow by condensation and/or aggregation. This delayed effect of $\mathrm{H}_{2}$, due to the presence of the capping agent, could then explain the larger size obtained from this procedure.

Synthesis in open air, under $\mathrm{O}_{2}$ flow, confirms the role of capping molecules on the growth process (Figure 5C). By using procedure I, only spherical nanocrystals similar to that obtained for platinum with the same procedure are obtained. Here, dodecylamine, added before the reducing agent, protects the seed from further growth. There is no specific action of $\mathrm{H}_{2}$, which is contuously being driven out by $\mathrm{O}_{2}$, so the size and shape are similar for palladium and platinum (Table 1 ). Palladium obtained by procedure II in open air (i.e., under $\mathrm{O}_{2}$ flow) (Figure 5D) is, however, strongly different compared to platinum. Large $(5.2 \pm 0.3 \mathrm{~nm}$, Table 1) and unshaped palladium NCs are collected after extraction. This strong increase in size, compared to procedure I, is what is usually expected by using the liquid-liquid phase transfer method and observed in the case of gold NCs. ${ }^{25}$ This shows that, different from the case of platinum, where worms are obtained by aggregation of spherical seeds (see above), the palladium seed can grow continuously by condensation of $\mathrm{Pd}^{0}$ on stable nuclei. This difference of behavior also indicates that the binding of dodecylamine with platinum is probably stronger than the binding of dodecylamine with palladium. This could be due to the nature of the metal and/or to the influence of oxygen on the anchoring of the dodecylamine. As a matter of fact, Figure 3C shows that, prior to the addition of dodecylamine, only isolated spherical NCs are obtained for palladium, different from the case of platinum where wormlike structures are observed (Figure 3A). Hence, growth occurs on isolated spherical seeds yielding larger NCs.

\section{CONCLUSION}

In summary, properly designed wet chemical synthesis, even in liquid isotropic solutions, offers a suitable way to produce anisotropic metallic nanoparticles and to control their shape at the nanoscopic scale. We have demonstrated the complexity of this process under several chemical conditions, where all the parameters could play an important role. Different from what is often reported, shape control of colloidally synthesized metallic NCs is not only due to the poisoning facets of crystalline seeds by halide such as $\mathrm{Br}^{-}$. We have demonstrated the primordial role of the dissolved gases issued either from air or as a byproduct of the reaction, which may strongly influence the shape of the NC. Indeed, they can perturb the dynamics of the capping layer at NC surfaces and also the nature of the metallic surfaces. This illustrates the complexity of the control of nanomorphology, as it needs fine-tuning of these various physicochemical parameters to establish a general framework of anisotropic growth of metallic nanoparticles in solution. Finally, it is demonstrated that platinum nanocubes are obtained only if $\mathrm{H}_{2}$ is present in solution.

\section{AUTHOR INFORMATION}

\section{Corresponding Author}

*E-mail: christophe.petit@upmc.fr.

\section{Notes}

The authors declare no competing financial interest.

\section{REFERENCES}

(1) Sau, T. K.; Rogach, A. L.; Jäckel, F; Klar, T. A.; Feldmann. Properties and Applications of Colloidal Nonsherical Noble Metal Nanoparticles. Adv. Mater. 2010, 22, 1805-1825.

(2) Brust, M.; Walker, M.; Bethell, D.; Schiffrin, D. J.; Whyman, R. Synthesis of thiol-derivatised gold nanoparticles in a two-phase Liquid-Liquid system. J. Chem. Soc., Chem. Commun. 1994, 7, 801802 .

(3) Brust, M.; Bethell, D.; Kiely, C. J.; Schiffrin, D. J. Self-Assembled Gold Nanoparticle Thin Films with Nonmetallic Optical and Electronic Properties. Langmuir 1998, 14, 5425-5429.

(4) Heath, J. R.; Knobler, C. M.; Leff, D. V. Pressure/Temperature Phase Diagrams and Superlattices of Organically Functionalized Metal Nanocrystal Monolayers: The Influence of Particle Size, Size Distribution, and Surface Passivant. J. Phys. Chem. B 1997, 101, 189-197.

(5) He, S.; Yao, J.; Jiang, P.; Shi, D.; Zhang, H.; Xie, S.; Pang, S.; Gao, H. Formation of Silver Nanoparticles and Self-Assembled TwoDimensional Ordered Superlattice. Langmuir 2001, 17, 1571-1575. 
(6) Beletskaya, I. P.; Cheprakov, A. V. The Heck Reaction as a Sharpening Stone of Palladium Catalysis. Chem. Rev. 2000, 100, 30093066.

(7) Biffis, A.; Zecca, M.; Basato, M. Palladium metal catalysts in Heck $\mathrm{C}=\mathrm{C}$ coupling reactions. J. Mol. Catal., A 2001, 173, 249-274.

(8) Nutt, M. O.; Hughes, J. B.; Wong, M. S. Designing Pd-on-Au Bimetallic Nanoparticle Catalysts for Trichloroethene Hydrodechlorination. Environ. Sci. Technol. 2005, 39, 1346-1353.

(9) Tanaka, H.; Uenishi, M.; Taniguchi, M.; Tan, I.; Narita, K.; Kimura, M.; Kaneko, K.; Nishihata, Y.; Mizuki. The intelligent catalyst having the self-regenerative function of $\mathrm{Pd}, \mathrm{Rh}$ and $\mathrm{Pt}$ for automotive emissions control. J. Catal. Today 2006, 117, 321-328.

(10) Kuji, T.; Matsumura, Y.; Uchida, H.; Aizawa, T. Hydrogen absorption of nanocrystalline palladium. J. Alloys Compd. 2002, 330, 718-722.

(11) Kishore, S.; Nelson, J. A.; Adair, J. H.; Eklund, P. C. Hydrogen storage in spherical and platelet palladium nanoparticles. J. Alloys Compd. 2005, 389, 234-242.

(12) Wang, C.; Daimon, H.; Lee, Y.; Kim, J.; Sun, S. Synthesis of monodisperse Ot Nanocubes and their enhanced catalysis for oxygen reduction. J. Am. Chem. Soc. 2007, 129, 6974-6975.

(13) Niu, W; Xu, G. Crystallographic control of noble metal nanocrystals. Nano Today 2011, 6, 265-285.

(14) Chen, M.; Wu, B.; Yang, J.; Zheng, N. Small Adsorbate-Assisted Shape Control of Pd and Pt Nanocrystals. Adv. Mater. 2012, 862-879.

(15) Filankembo, A.; Giorgio, S.; Lisiecki, I.; Pileni, M. P. Is the Anion the Major Parameter in the Shape Control of Nanocrystals? J. Phys. Chem. B 2003, 107, 7492-7500.

(16) Demortière, A.; Launois, P.; Goubet, N.; Albouy, P. A.; Petit, C. Shape-Controlled Platinum Nanocubes and Their Assembly into TwoDimensional and Three-Dimensional Superlattices. J. Phys. Chem. B 2008, 112, 14583-14592.

(17) Xia, Y.; Xiong, Y.; Lim, B.; Skrabalak, S. E. Shape-Controlled Synthesis of Metal Nanocrystals: Simple Chemistry Meets Complex Physics? Angew. Chem. Int. Ed 2008, 48, 60-103.

(18) Peng, Z.; Kisielowski, C.; Bell, A. T. Surfactant free preparation of supported cubic platinum nanoparticles. Chem. Commun. 2012, 48, $1854-1856$.

(19) Wikander, K.; Petit, C.; Holmberg, K.; Pileni, M.-P. Size Control and Growth Process of Alkylamine-Stabilized Platinum Nanocrystals: A Comparison between the Phase Transfer and Reverse Micelles Methods. Langmuir 2006, 22, 4863-4868.

(20) Naoe, K.; Petit, C.; Pileni, M.-P. From Wormlike to Spherical Palladium Nanocrystals: Digestive Ripening. J. Phys. Chem. C 2007, 111, 16249-16254.

(21) Gonzales, N. O.; Levin, M. E.; Zimmerman, L. W. The reactivity of sodium borohydride with various species as characterized by adiabatic calorimetry. J. Haz. Mater. 2007, 142, 639-646.

(22) Glavee, G. N; Klabunde, K. J.; Sorensen, C. M.; Hadjapanayis, G. C. Borohydride reductions of metal ions. A new understanding of the chemistry leading to nanoscale particles of metals, borides, and metal borates. Langmuir 1992, 8, 771-773.

(23) Legrand, J.; Taleb, A.; Gota, S.; Guittet, M. J.; Petit, C. Synthesis and XPS Characterization of Nickel Boride Nanoparticles. Langmuir 2002, 18, 4131-4137.

(24) Wagman, D. D.; et al. The NBS tables of chemical thermodynamic properties. Selected values for inorganic and $\mathrm{C} 1$ and C2 organic substances in SI units. J. Phys. Chem. Ref. Data 1982, 11 (Suppl), 2.

(25) Brust, M.; Bethell, D.; Schiffrin, D. J.; Kiely, C. J. Novel golddithiol nano-networks with non-metallic electronic properties. Adv. Mater. 1995, 7, 795-797.

(26) Dahmani, C. E.; Cadeville, M. C.; Pierron-Bonhes, V. Temperature dependences of atomic order relaxations in NiPt and CoPt alloys. Acta Metall. 1985, 33, 369-377.

(27) Peng, Z.; Yang, S.; Yang, H. Approaches to the synthesis and characterization of spherical and anisotropic platinum nanomaterials; In Nanotechnologies for the life sciences, Kumar, Challa S. S. R., Ed.; Wiley-VCH: Weinhem, 2008; Vol 1 Metallic Nanomaterials, p 357.
(28) Burch, R. Chemical Physics of Solids and Their Surfaces; Royal Society of Chemistry, 1980; Vol 8, p 1.

(29) Rzeszotarski, P.; Kaszkur, Z. Surface reconstruction of Pt nanocrystals interacting with gas atmosphere. Bridging the pressure gap with in situ diffraction. Phys. Chem. Chem. Phys. 2009, 11, 54165421.

(30) Niehus, H.; Comsa, G. Surface and subsurface oxygen adsorbed on Pt(111). Surf. Sci. 1980, 93, L147-L150.

(31) Shiao, S. Y.; Chabra, V.; Patist, A.; Free, M. L.; Huibers, P. D. T.; Gregory, A.; Patel, S.; Shah, D. O. Chain length compatibility effects in mixed surfactant systems for technological applications. Adv. Colloid Interface Sci. 1998, 74, 1-29.

(32) Dassenoy, F.; Philippot, K.; Ould Ely, T.; Amiens, C.; Lecante, P.; Snoeck, E.; Mosset, A.; Casanove, M.-J.; Chaudret, B. Platinum nanoparticles stabilized by $\mathrm{CO}$ and octanethiol ligands or polymers: FT-IR, NMR, HREM and WAXS studies. New J. Chem. 1998, 22, $703-712$.

(33) Salzeman, C.; Petit, C.; Andreazza, P. , manuscript in preparation.

(34) Ibañez, F., J.; Zamborini, F. P. Reactivity of Hydrogen with Solid-State Films of Alkylamine- and Tetraoctylammonium BromideStabilized Pd, PdAg, and PdAu Nanoparticles for Sensing and Catalysis Applications. J. Am. Chem. Soc. 2008, 130, 622-633.

(35) Joshi, R., K.; Krishnan, S.; Yoshimura, M.; Kumar, A. Nanoscale Res. Lett. 2009, 4, 1191. 